\title{
Aspects of Oral Language, Speech, and Written Language in Subjects with Temporal Lobe Epilepsy of Difficult Control
}

\author{
Ana Paula Berberian ${ }^{1}$ Christiane Hopker ${ }^{1}$ Ingrid Mazzarotto ${ }^{1}$ Jenane Cunha ${ }^{1}$ \\ Ana Cristina Guarinello ${ }^{1}$ Giselle Massi ${ }^{1}$ Ana Crippa ${ }^{2}$
}

${ }^{1}$ Masters and Doctorate Program in Communication Disorders, Universidade Tuiuti do Paraná, Curitiba, Paraná, Brazil

${ }^{2}$ Department of Neurophysiology, Universidade Federal do Paraná, Curitiba, Brazil
Address for correspondence Ana Cristina Guarinello, PhD, Masters and Doctoral Program of Communication Disorders, University Tuiuti of Paraná, Alexandre Eduardo Klat, 66 casa 2, Curitiba 82130-120, Brazil (e-mail: acguarinello@gmail.com).

Int Arch Otorhinolaryngol 2015;19:302-308.

\begin{abstract}
Keywords

- epilepsy

- language

- reading

- speech-language and hearing sciences

Introduction About 50 million people have epilepsy and 30\% of them have epilepsy that does not respond to properly conducted drug treatment.

Objective Verify the incidence of language disorders in oral language, speech, and written language of subjects with difficult to control temporal lobe epilepsy (TLE) and compare the occurrence of these disorders in subjects before and after surgery.

Methods Cross-sectional study with quantitative analysis, exploratory type. A questionnaire for data collection was administered covering the following aspects: oral language, speech complaints, and writing production and comprehension. Criteria for inclusion of subjects were a diagnosis of TLE refractory to drug treatment and at least 4 years of schooling.

Results The sample of 63 patients with TLE was divided into two groups: presurgical $(n=31)$ and postsurgical $(n=32)$. In the postsurgical group, there was a higher frequency of left lobectomy (75\%) than right (25\%).

Conclusion Statistical analysis was performed with the chi-square test (significance level of 0.05 ). Complaints related to speech-language attention were more predominant in postsurgical subjects. Analysis of oral language, speech, and written language in subjects with epilepsy who underwent temporal lobectomy or not showed findings consistent with symptoms related to transient aphasia, with the presence of paraphasias, as well as changes in speech prosody and melody. These symptoms appeared more associated with recurrence after having a temporal lobectomy.
\end{abstract}

\section{Introduction}

About 50 million people suffer from epilepsy with active seizures and $30 \%$ of them have refractory epilepsy (i.e., no response to properly conducted drug treatment). ${ }^{1}$ Temporal lobe epilepsy (TLE) is the most common form of epilepsy in adults. It is specific, with a high level of incidence and severity, and is characterized by the presence of simple and complex partial seizures. The temporal lobe can be divided into medial (playing an important role in episodic and autobiographical memory, coding, and temporal ordering of events in verbal memory, and visuospatial memory) as well as neocortical (related to semantic memory). ${ }^{2}$

Temporal lobectomy controls seizures in up to $70 \%$ of refractory epilepsy cases, but when found in the left received

December 10, 2014

accepted

January 26, 2015

published online

March 10, 2015
DOI http://dx.doi.org/

10.1055/s-0035-1547524. ISSN $1809-9777$.
Copyright $(2015$ by Thieme Publicações License terms Ltda, Rio de Janeiro, Brazil
(1) (1) $\Theta \circledast$ 
hemisphere, it can impair oral language functions, especially related to naming. ${ }^{3}$ Diminishment in verbal memory is also reported as a common effect after surgery on the dominant hemisphere of the temporal lobe. ${ }^{4-7}$ Studies show that patients who undergo temporal lobectomy may present deficits in semantic access in some tasks using work recovery. ${ }^{8}$ Examining the efficiency of lexical and semantic processing, in association with the activation of the brain, one realizes that a temporal lobectomy is associated with a failure in the functional organization of cortical networks involved in lexical and semantic processing. ${ }^{9}$

The resection of the temporal lobe can bring risks to verbal and visual episodic memory, as well as naming. Studies have reported declining naming and semantic functions postoperatively, suggesting the hypothesis that naming deficits arise from the functional specialization of the left temporal lobe and the semantic interpretation of visual input. ${ }^{10,11}$ Studies pointed to the fact that patients with left resection showed anomia in simple semantic tasks and that with increasing complexity of the task, they showed semantic deficit. ${ }^{5}$ Studies also have focused on brain reorganization for the processing of oral language during the postsurgical period. ${ }^{3,12,13}$ In the preoperative period, aspects of determining the dominant hemisphere of oral language, which is critical in planning surgical procedures, are being investigated. ${ }^{14}$

Regarding written language, one study compared reading skills (comprehension and sentence recognition, as well as memory accuracy, fluency, and complexity) in patients after a left temporal resection with those from a control group. ${ }^{15}$ Findings showed that, after surgery, proficiency in reading remains preserved due to a compensation mechanism of the right hemisphere coupled with integration of activated brain areas in the process.

Although surgical resection is common for the treatment of refractory TLE, the literature dealing with possible changes in oral language, speech, and written language in patients undergoing temporal lobectomy is scarce, a factor that justifies this study.

Considering the multidimensional impacts of epilepsy, including those that are linguistic and psychological, this study aims to verify the incidence of language disorders in oral language, speech, and writing language in subjects with TLE that is difficult to control and compare the occurrence of these disorders before and after surgery.

\section{Methods}

This is a cross-sectional, quantitative, exploratory study conducted in the Adult Epilepsy Clinic. This integrated epilepsy care program is a referral center in the Public Health System in Brazil and serves patients referred from various regions of the country. Clinic consultations occur in two stages: presurgical and postsurgical monitoring ( $\sim 40$ consultations per month) and intractable epilepsy patients ( 180 consultations per month).

\section{Evaluation}

For data collection, a questionnaire with open and closed questions was given to subjects by a nurse and a speech therapist, averaging 30 minutes in duration. After that, a speech-language therapist applied a speech-language evaluation. Both tools have questions encompassing speech complaints, as well as speech and writing for both production and comprehension. Inclusion criteria for the study were having a diagnosis of refractory TLE (i.e., no response to properly conducted drug treatment) and at least 4 years of schooling. Patients who did not properly follow drug treatment or medical management were excluded. The questionnaire was answered after reading and signing the consent form.

\section{Participants}

The sample was comprised of 63 patients with TLE divided into two groups: presurgical (PRE-CIR; $n=31$ ) and postsurgical (POS-CIR; $n=32$ ). The PRE-CIR group was composed of 20 female (64.5\%) and 11 male (35.5\%) subjects with mean age of 40.4 years (standard deviation 12.7). In this group there was a higher prevalence of left TLE $(n=14)$, followed by right TLE $(n=9)$ and bilateral TLE $(n=8)$. The POS-CIR group was composed of 15 female (46.9\%) and 17 male (53.1\%) subjects, with mean age of 39.7 years (standard deviation 9.6). In this group there was a predominance of left TLE $(n=14)$, followed by right TLE $(n=9)$ and bilateral TLE $(n=8)$. There was a higher frequency of left lobectomy, $75 \%(n=24)$, with right making up $25 \%(n=8)$. The time interval between the temporal lobectomy and data collection ranged from 1 to 39 months.

\section{Analysis}

Statistical analysis was performed by applying the chi-square test (significance level $p<0.05$ ).

\section{Ethics}

The project was approved by the Ethics Committee registration number 380977, CAAE: 18218413.9.0000.0096 of Sep 9, 2013.

\section{Results}

Of the total respondents, $68 \%$ presented with one or more aspects of interest to speech-language pathology and $62 \%$ had a change in the area of language. The aforementioned complaints were related to chewing, swallowing, hearing, vestibular system, and voice ( - Table $\mathbf{1}$ ).

Using the chi-square test, the POS-CIR group presented a more significant proportion of speech-language pathology complaints.

In the POS-CIR group, chewing alterations were more frequent, with $25 \%$ describing difficulty in opening their mouth (lasting 1 to 3 months after surgery). With swallowing, $6.2 \%$ reported pain for $\sim 20$ days postoperatively. Tinnitus, ear pain, and ear fullness were cited as hearing issues by $21.9 \%$ of participants. Dizziness (3.1\%) and weak vocal emissions (3.1\%) were also identified among the complaints. 
Table 1 Distribution of the sample according to speech-language pathology complaints

\begin{tabular}{|l|l|l|l|}
\hline \multirow{2}{*}{ Complaints } & Groups & \multicolumn{2}{|l|}{$p$} \\
\cline { 2 - 3 } & POS-CIR $(\boldsymbol{n}=32)$ & PRE-CIR $(\boldsymbol{n}=31)$ \\
\hline None & $15(46.9 \%)$ & $28(90.3 \%)$ \\
\hline Chewing & $8(25.0 \%)$ & $-(0.0 \%)$ \\
\hline Swallowing & $2(6.2 \%)$ & $1(3.2 \%)$ \\
\hline Hearing & $7(21.9 \%)$ & $2(6.4 \%)$ \\
\hline Vestibular system & $1(3.1 \%)$ & $-(0.0 \%)$ \\
\hline Voice & $1(3.1 \%)$ & $-(0.0 \%)$ \\
\hline
\end{tabular}

Abbreviations: POS-CIR, after frontal lobotomy; PRE-CIR, before frontal lobotomy.

${ }^{*}$ Chi-square, significance level of 0.05 .

Frequent changes to speech production were speech rate (12.6\%), prosody (8\%), and speech intelligibility (8\%). When comparing PRE-CIR and POS-CIR groups using the chi-square test, there was a significant difference only for the speech rate, with an appropriate speed being better among PRE-CIR subjects (-Table 2). For the application of the test, the following variables were considered: phonological aspects, speech rate, prosody, as well as discourse understanding and structure.

To analyze possible changes in oral language related to the surgical procedure, pre- and postprocedure complaints (for POS-CIR) and current complaints (for PRE-CIR) were investigated. The subjects' responses were forgetting and missing words, anomia, paraphasia, memory loss, and stuttering (-Table 3). Regarding these aspects, no significant differences between groups were observed. It is noteworthy that for application of the test, answers of none and no complaint were considered.

From the perception of the subjects, alterations and/ or improvements in oral language and speech production and comprehension after surgery (POS-CIR) were investigated. The answers were classified as forgetting and missing words, anomia, paraphasia, memory loss, worsening of preexisting symptoms of stuttering/speech/memory, and difficulty in articulation (-Table 4 ).

Of the total POS-CIR subjects, 53\% of participants reported some disorder. The most frequent complaints were forgetting and missing words (25\%), paraphasia (12.5\%), and worsening of preexisting symptoms of stuttering, speech, and memory (12.5\%).

On the patient's perception of improvement in oral language and speech, after surgery, $12.5 \%$ reported feeling increased competence to speak and improvement in their emotional state to talk.

The relationship between oral language and speech disorders and surgery was not statistically significant, although a higher incidence of alterations was observed in patients with left TLE ( - Table 5).

Through the chi-square test, there was no significant difference in any case. To implement the test we considered the response categories: phonological aspects (omissions and distortions + substitutions), speech rate (adequate and fast + slow), prosody (adequate and monotone).

Results related to the reading and writing results are described in - Table $\mathbf{6}$. There were no statistically significant differences between groups related to written language; however, the PRE-CIR group showed a higher percentage of disorders, with $16.1 \%$ in reading comprehension and $12.9 \%$ in writing production.

Regarding disorders after surgery, $6.2 \%$ of participants reported difficulties related to the formal aspects (spelling) and $6.2 \%$ had difficulties understanding the written text.

\section{Discussion}

Complaints related to speech-language pathology were more predominant in POS-CIR subjects. It can be inferred that complaints related to chewing, swallowing, and hearing can be caused by the surgical procedure because the temporomandibular joint is composed of an articulating area whose concave depression lies in a portion of the temporal bone, an area manipulated during the lobectomy procedure, and is also in close proximity to the auditory system. Complaints regarding vocal ability may be related to the endotracheal or tracheal intubation procedure used for auxiliary support in artificial ventilation.

As for speech, the comparison between the POS-CIR and PRE-CIR groups showed statistically significant differences only for the alteration in rate of speech in the POS-CIR subjects. No studies that indicate similar findings were found.

There are references in the literature to the problems of speech production, as well as findings of our study, on the correlation between epilepsy and changes in prosody. ${ }^{16}$ In addition, regarding oral language, both groups presented alterations as missing words, anomia, paraphasia, memory loss, and stuttering.

According to the literature, it appears that TLE has been associated with such alterations because the epileptogenic zone is located in the temporal lobe dominant for such functions. And TLE is also associated with dysfunction in memory when it involves the temporal lobes of both hemispheres. $^{17}$ The occurrence of symptoms classified as 
Table 2 Distribution of the sample according to aspects of oral language and speech

\begin{tabular}{|c|c|c|c|}
\hline & \multicolumn{2}{|l|}{ Groups } & \multirow[t]{2}{*}{$p$} \\
\hline & POS-CIR $(n=32)$ & PRE-CIR $(n=31)$ & \\
\hline \multicolumn{4}{|l|}{ I-Speech production } \\
\hline Articulation & & & 0.1572 \\
\hline Adequate & $30(93.8 \%)$ & $31(100 \%)$ & \\
\hline Blocked & $2(6.2 \%)$ & $-(0.0 \%)$ & \\
\hline Phonological aspects & & & 0.1572 \\
\hline Adequate & $30(93.8 \%)$ & $31(100 \%)$ & \\
\hline Omissions & $1(3.1 \%)$ & $-(0.0 \%)$ & \\
\hline Distortions & $-(0.0 \%)$ & $-(0.0 \%)$ & \\
\hline Substitutions & $1(3.1 \%)$ & $-(0.0 \%)$ & \\
\hline Unintelligible speech & & & 0.1734 \\
\hline Not compromised & $28(87.5 \%)$ & $30(96.8 \%)$ & \\
\hline Slightly compromised & $4(12.5 \%)$ & $1(3.2 \%)$ & \\
\hline Speed of speech & & & $0.0263^{*}$ \\
\hline Adequate & $25(78.1 \%)$ & $30(96.8 \%)$ & \\
\hline Fast & $2(6.2 \%)$ & $-(0.0 \%)$ & \\
\hline Slow & $5(16.6 \%)$ & $1(3.2 \%)$ & \\
\hline Prosody & & & 0.1617 \\
\hline Adequate & $27(84.4 \%)$ & $30(96.8 \%)$ & \\
\hline Monotone & $4(12.5 \%)$ & $1(3.2 \%)$ & \\
\hline Inconclusive & $1(3.1 \%)$ & $-(0.0 \%)$ & \\
\hline \multicolumn{4}{|c|}{ II-Comprehension and structuring of oral language } \\
\hline Comprehension & & & 0.5354 \\
\hline Not compromised & $31(96.9 \%)$ & $29(93.5 \%)$ & \\
\hline Slightly compromised & $1(3.1 \%)$ & $2(6.4 \%)$ & \\
\hline Structuring & & & 0.572 \\
\hline Present & $30(93.8 \%)$ & $31(100 \%)$ & \\
\hline Partial & $2(6.2 \%)$ & $-(0.0 \%)$ & \\
\hline
\end{tabular}

Abbreviations: POS-CIR, after frontal lobotomy; PRE-CIR, before frontal lobotomy. ${ }^{*}$ Chi-square, significance level of 0.05 .

Table 3 Distribution of the sample according to oral language

\begin{tabular}{|l|l|l|l|}
\hline \multirow{2}{*}{ Complaints } & \multicolumn{2}{|l|}{ Groups } & \multirow{2}{*}{$p$} \\
\cline { 2 - 3 } & Pos-CIR $(\boldsymbol{n}=32)$ & Pre-CIR $(\boldsymbol{n}=31)$ & \\
\hline None & $24(75.0 \%)$ & $18(58.1 \%)$ & 0.2414 \\
\hline Forgetting and missing words & $6(18.8 \%)$ & $3(9.7 \%)$ & \\
\hline Anomia & $1(3.2 \%)$ & $4(12.9 \%)$ & \\
\hline Paraphasias & $-(0.0 \%)$ & $2(6.4 \%)$ & \\
\hline Memory loss & $-(0.0 \%)$ & $5(16.1 \%)$ & \\
\hline Stuttering & $5(15.6 \%)$ & $2(6.4 \%)$ & \\
\hline
\end{tabular}

Abbreviations: POS-CIR, after frontal lobotomy; PRE-CIR, before frontal lobotomy. ${ }^{*}$ Chi-square, significance level of 0.05 . 
Table 4 Distribution of sample according to postsurgery oral language and speech complaints $(n=32)$

\begin{tabular}{|l|l|}
\hline Complaint & Frequency (\%) \\
\hline None & $15(46.9 \%)$ \\
\hline $\begin{array}{l}\text { Forgetting and } \\
\text { missing words }\end{array}$ & $8(25.0 \%)$ \\
\hline Anomia & $3(9.4 \%)$ \\
\hline Paraphasia & $4(12.5 \%)$ \\
\hline $\begin{array}{l}\text { Worsening of } \\
\text { memory }\end{array}$ & $3(9.4 \%)$ \\
\hline $\begin{array}{l}\text { Worsening of stut- } \\
\text { tering, speech, and } \\
\text { memory }\end{array}$ & $4(12.5 \%)$ \\
\hline $\begin{array}{l}\text { Difficulty } \\
\text { articulating }\end{array}$ & $1(3.1 \%)$ \\
\hline
\end{tabular}

forgetting and missing words are frequently reported by patients with TLE. ${ }^{18,19}$

In our study, we found that paraphasias corroborated another study in which, after having a temporal lobectomy, patients identified deficits in semantic retrieval tasks with words, showing paraphasias. ${ }^{8}$

Naming difficulties also were described in the literature after left temporal lobe surgery. ${ }^{3,20,21}$ Naming deficits were observed only in patients with left TLE and yet a significant association was found between the decline of postoperative naming and prejudice to semantic functions. ${ }^{11}$ Naming has been identified in regions of the cortex involved in oral language. Studies show that patients with TLE have no difficulty in naming concrete objects that were visually presented to them. However, before and after surgery, they often show difficulty in finding words in their daily activities (forgetting/missing words, anomia). ${ }^{22}$

Table 5 Relationship between aspects of speech and oral language and surgery side

\begin{tabular}{|c|c|c|c|}
\hline & \multicolumn{2}{|c|}{ Side of surgery } & \multirow[t]{2}{*}{$p$} \\
\hline & Left $(n=24)$ & Right $(n=8)$ & \\
\hline \multicolumn{4}{|l|}{ I-Speech production } \\
\hline \multicolumn{4}{|l|}{ Articulation } \\
\hline Adequate & $22(68.8 \%)$ & $8(25.0 \%)$ & \multirow[t]{2}{*}{0.3991} \\
\hline Blocked & $2(6.2 \%)$ & $-(0.0 \%)$ & \\
\hline \multicolumn{4}{|l|}{ Speech-language aspects } \\
\hline Adequate & $22(68.8 \%)$ & $8(25.0 \%)$ & \multirow[t]{3}{*}{0.3991} \\
\hline Distortions & $1(3.1 \%)$ & $-(0.0 \%)$ & \\
\hline Substitutions & $1(3.1 \%)$ & $-(0.0 \%)$ & \\
\hline \multicolumn{4}{|l|}{ Unintelligible speech } \\
\hline Not compromised & $21(65.6 \%)$ & 7 (21.9\%) & \multirow[t]{2}{*}{$>0.9999$} \\
\hline Slightly compromised & $3(9.4 \%)$ & $1(3.1 \%)$ & \\
\hline \multicolumn{4}{|l|}{ Speed of speech } \\
\hline Adequate & $18(56.2 \%)$ & $7(21.9 \%)$ & \multirow[t]{3}{*}{0.4589} \\
\hline Fast & $2(6.2 \%)$ & $-(0.0 \%)$ & \\
\hline Slow & $4(12.4 \%)$ & $1(3.2 \%)$ & \\
\hline \multicolumn{4}{|l|}{ Prosody } \\
\hline Adequate & $21(65.6 \%)$ & $6(18.8 \%)$ & \multirow[t]{3}{*}{0.9013} \\
\hline Monotone & $3(9.4 \%)$ & $1(3.1 \%)$ & \\
\hline Inconclusive & $-(0.0 \%)$ & $1(3.1 \%)$ & \\
\hline \multicolumn{4}{|c|}{ II-Comprehension and structuring of oral language } \\
\hline \multicolumn{4}{|l|}{ Comprehension } \\
\hline Not compromised & $23(71.9 \%)$ & $8(25.0 \%)$ & \multirow[t]{2}{*}{0.5575} \\
\hline Slightly compromised & $1(3.1 \%)$ & $-(0.0 \%)$ & \\
\hline \multicolumn{4}{|l|}{ Structuring } \\
\hline Present & $23(71.9 \%)$ & $7(21.9 \%)$ & \multirow[t]{2}{*}{0.3991} \\
\hline Partial & $1(3.1 \%)$ & $1(3.1 \%)$ & \\
\hline
\end{tabular}

${ }^{*}$ Chi-square, significance level of 0.05 . 
Table 6 Distribution of the sample according to aspects of reading and writing

\begin{tabular}{|c|c|c|c|}
\hline \multirow[t]{2}{*}{ Written Language } & \multicolumn{2}{|l|}{ Groups } & \multirow[t]{2}{*}{$p$} \\
\hline & POS-CIR $(n=32)$ & PRE-CIR $(n=31)$ & \\
\hline \multicolumn{4}{|l|}{ Reading } \\
\hline Fluent & $2(87.5 \%)$ & $25(80.6 \%)$ & \multirow[t]{4}{*}{0.4567} \\
\hline Fluency compromised & $3(9.4 \%)$ & $-(0.0 \%)$ & \\
\hline Inconclusive & $1(3.1 \%)$ & $1(3.2 \%)$ & \\
\hline Doesn't read & $-(0.0 \%)$ & $5(16.1 \%)$ & \\
\hline \multicolumn{4}{|l|}{ Reading comprehension } \\
\hline Yes & $29(90.6 \%)$ & $23(74.2 \%)$ & \multirow[t]{3}{*}{0.0695} \\
\hline No & $1(3.1 \%)$ & $5(16.1 \%)$ & \\
\hline Inconclusive & $2(6.2 \%)$ & $3(9.7 \%)$ & \\
\hline \multicolumn{4}{|l|}{ Reading and writing complaints } \\
\hline None & $31(96.9 \%)$ & $26(83.9 \%)$ & \multirow[t]{3}{*}{0.0788} \\
\hline Severe difficulties or impossible in writing & $1(3.1 \%)$ & $4(12.9 \%)$ & \\
\hline Severe difficulties or impossible in reading & $-(0.0 \%)$ & $1(3.2 \%)$ & \\
\hline \multicolumn{4}{|l|}{ Written language notification post surgery } \\
\hline None & $28(87.5 \%)$ & $-(0.0 \%)$ & \\
\hline Orthographic aspects & $2(6.2 \%)$ & $-(0.0 \%)$ & \\
\hline Semantic aspects in reading & $2(6.2 \%)$ & $-(0.0 \%)$ & \\
\hline Semantic aspects in writing & $1(3.1 \%)$ & $-(0.0 \%)$ & \\
\hline Illiterate & $1(3.1 \%)$ & $-(0.0 \%)$ & \\
\hline
\end{tabular}

Abbreviations: POS-CIR, after frontal lobotomy; PRE-CIR, before frontal lobotomy.

${ }^{*}$ Chi-square, significance level of 0.05 .

As with the findings of this study, previous research found that TLE is associated with alterations to the functioning of episodic long-term memory, and recovery processes and immediate recognition (short-term memory) appear less affected. ${ }^{23-25}$ The effect of epilepsy on memory and forgetting words is better understood in mesial TLE with hippocampal sclerosis, because the hippocampus and entorhinal cortex neighbors are involved in the formation of declarative memory. As the verbal episodic memory is strongly associated with the dominant hemisphere, patients with left mesial TLE, in general, exhibit deficits in consolidation and recovery of verbal memory. In cases where the epileptic focus is located in the nondominant hemisphere, visuospatial memory may be affected. ${ }^{26}$

One study demonstrated the link between problems with long-term memory and TLE, because the mesial temporal lobe plays a prominent role in memory. ${ }^{27}$ Subjects with TLE tend to show amnesic alterations. ${ }^{28}$ Other aspects of amnesic function may be factors such as remote, autobiographical, and semantic memory. ${ }^{29}$

Most participants still had fluent reading skills and comprehension, and there was no significant difference between PRE-CIR and POST-CIR in aspects of reading and reading comprehension, which corroborates with the literature. ${ }^{15} \mathrm{~A}$ higher occurrence of changes related to reading comprehension and written production was cited by the PRE-CIR group, corroborating prior studies..$^{30,31}$

\section{Conclusion}

In the analysis of aspects of oral language, speech, and written language, subjects with epilepsy who did or did not undergo a temporal lobectomy showed findings consistent with the symptoms related to transient aphasia, with the presence of paraphasias, as well as changes in speech prosody and melody. These symptoms are peculiar and appear with higher frequency when associated with temporal lobectomy surgery. The study highlighted the need to implement research that addresses implications in speech and written language sciences for people with epilepsy.

\section{References}

1 Epilepsy WHO. Epilepsy. Available at: http://www.who.int/mediacentre/factsheets/fs999/en/index.html. Accessed May 26, 2012

2 Damasceno BP, Mitidieri ACH. Percepção do tempo em pacientes com epilepsia submetidos a lobectomia temporal anteromedial. Relatório Fapesp. Campinas SP, Brazil: Universidade Estadual de Campinas (UNICAMP); 2013

3 Bonelli SB, Thompson PJ, Yogarajah M, et al. Imaging language networks before and after anterior temporal lobe resection: results of a longitudinal fMRI study. Epilepsia 2012;53(4):639-650

4 Tracy JI, Osipowicz K, Godofsky S, et al. An investigation of implicit memory through left temporal lobectomy for epilepsy. Neurobiol Learn Mem 2012;98(3):272-283 
5 Lambon RMA, Ehsan S, Baker GA, Rogers TT. Semantic memory is impaired in patients with unilateral anterior temporal lobe resection for temporal lobe epilepsy. Brain. J Neurol 2012;135(1):242-258

6 Binder JR, Swanson SJ, Sabsevitz DS, Hammeke TA, Raghavan M, Mueller WM. A comparison of two fMRI methods for predicting verbal memory decline after left temporal lobectomy: language lateralization versus hippocampal activation asymmetry. Epilepsia 2010;51(4):618-626

7 Wagner K, Uherek M, Horstmann S, et al. Memory outcome after hippocampus sparing resections in the temporal lobe. J Neurol Neurosurg Psychiatry 2013;84(6):630-636

8 Protzner AB, McAndrews MP. Network alterations supporting word retrieval in patients with medial temporal lobe epilepsy. J Cogn Neurosci 2011;23(9):2605-2619

9 Jensen EJ, Hargreaves IS, Pexman PM, Bass A, Goodyear BG, Federico P. Abnormalities of lexical and semantic processing in left temporal lobe epilepsy: an fMRI study. Epilepsia 2011;52(11): 2013-2021

10 Hamberger MJ, Seidel WT, McKhann GM II, Goodman RR. Hippocampal removal affects visual but not auditory naming. Neurology 2010;74(19):1488-1493

11 Schwarz M, Pauli E. Postoperative speech processing in temporal lobe epilepsy: functional relationship between object naming, semantics and phonology. Epilepsy Behav 2009;16(4):629-633

12 Tivarus ME, Starling SJ, Newport EL, Langfitt JT. Homotopic language reorganization in the right hemisphere after early left hemisphere injury. Brain Lang 2012;123(1):1-10

13 Moser DC, Papanicolaou AC, Swank P, Breier JI. Evidence for the solidarity of the expressive and receptive language systems: a retrospective study. J Int Neuropsychol Soc 2011;17(1):62-68

14 Pirmoradi M, Béland R, Nguyen DK, Bacon BA, Lassonde M. Language tasks used for the presurgical assessment of epileptic patients with MEG. Epileptic Disord 2010;12(2):97-108

15 Noppeney U, Price CJ, Duncan JS, Koepp MJ. Reading skills after left anterior temporal lobe resection: an fMRI study. Brain 2005;128 (Pt 6):1377-1385

16 Peters AS, Rémi J, Vollmar C, Gonzalez-Victores JA, Cunha JP, Noachtar S. Dysprosody during epileptic seizures lateralizes to the nondominant hemisphere. Neurology 2011;77(15):1482-1486

17 Rzezak P, Fuentes D, Guimarães CA, Guerreiro M, Valente KDR. A Disfunção do Lobo Frontal em Crianças e Adolescentes com Epilepsia de Lobo Temporal e sua Possível Correlação com a Ocorrência de Transtornos Psiquiátricos. J Epilepsy Clinical Neurophysiol 2005;11(3):131-136
18 Guimarães CA, Min LL, Rzezak P. Memory impairment in children with temporal lobe epilepsy: a review. J Epilepsy Clinical Neurophysiol 2006;12(1):22-25

19 Trebuchon-Da Fonseca A, Guedj E, Alario FX, et al. Brain regions underlying word finding difficulties in temporal lobe epilepsy. Brain 2009;132(Pt 10):2772-2784

20 Bartha L, Trinka E, Ortler M, et al. Linguistic deficits following left selective amygdalohippocampectomy: a prospective study. Epilepsy Behav 2004;5(3):348-357

21 Sabsevitz DS, Swanson SJ, Hammeke TA, et al. Use of preoperative functional neuroimaging to predict language deficits from epilepsy surgery. Neurology 2003;60(11):1788-1792

22 Powell HW, Parker GJ, Alexander DC, et al. Imaging language pathways predicts postoperative naming deficits. J Neurol Neurosurg Psychiatry 2008;79(3):327-330

23 Hamberger MJ, Seidel WT, McKhann GM II, Perrine K, Goodman RR. Brain stimulation reveals critical auditory naming cortex. Brain 2005;128(Pt 11):2742-2749

24 Busch NA, Groh-Bordin C, Zimmer HD, Herrmann CS. Modes of memory: early electrophysiological markers of repetition suppression and recognition enhancement predict behavioral performance. Psychophysiology 2008;45(1):25-35

25 Yancey SW, Phelps EA. Functional neuroimaging and episodic memory: a perspective. J Clin Exp Neuropsychol 2001;23(1): 32-48

26 Dickerson BC, Eichenbaum H. The episodic memory system: neurocircuitry and disorders. Neuropsychopharmacology 2010; 35(1):86-104

27 Oliveira GNM, Kummer A, Salgado JV, Marchetti Rl, Teixeira AL Transtornos Neuropsiquiátricos da Epilepsia do Lobo Temporal. Rev Bras Neurol 2009;45(1):15-23

28 Hendriks MPH, Aldenkamp AP, Alpherts WC, Ellis J, Vermeulen J, van der Vlugt $H$. Relationships between epilepsy-related factors and memory impairment. Acta Neurol Scand 2004;110(5): 291-300

29 Hötting K, Katz-Biletzky T, Malina T, Lindenau M, Bengner T. Longterm versus short-term memory deficits for faces in temporal lobe and generalized epilepsy patients. J Int Neuropsychol Soc 2010; 16(3):574-578

30 Bell BD, Giovagnoli AR. Recent innovative studies of memory in temporal lobe epilepsy. Neuropsychol Rev 2007;17(4):455-476

31 Butterbaugh G, Olejniczak P, Roques B, et al. Lateralization of temporal lobe epilepsy and learning disabilities, as defined by disability-related civil rights law. Epilepsia 2004;45(8):963-970 